\title{
The Broken Mirror: The Identity of the Text in Shelley's Triumph of Life
}

$\mathrm{I}^{\mathrm{n}}$

n Prometheus Unbound Shelley goes as far as he can in separating the pragmatic from the metaphysical, the positive activity of reading or more properly acting out, from what he sees as the deconstructive activity of writing. But there is something evasive about this solution. Denying that reading can return us to a point of origin, the play nevertheless affirms that it can enact a work identical with itself. For in making his text into a play, Shelley allegorizes reading as performance rather than interpretation, a discourse that legitimizes itself by doing what it says rather than by conveying an anterior and provable truth. At the end of her encounter with Demogorgon, Asia gives up the attempt to interpret anything and simply acts as if certain suppositions were true. We are not bound by these suppositions, since the fourth act is a masque that knows itself to be sustained only by Demogorgon's rough magic. ${ }^{1}$ Yet if we stand back from the play, we begin to sense that Prometheus Unbound only represents a solution. For the notion of reading as performance ignores the fact that there is no such thing as an act of pure will unmediated by language. Or to put it differently, it avoids recognizing that performance also occurs in a linguistic world. Indeed, in one of the manuscript versions of the Defence Shelley sees perception or poetry, expression or art, and "invention" or "the application of art" to knowledge and use, as gradations of the same power, thus implying that they

${ }^{1}$ For a discussion of how the lyrical elements in Shelley's lyrical drama, particularly in the fourth act, provide a Dionysiac undertow that threatens to dissolve the Apollonian fiction, see Ross Woodman, "Nietzsche, Blake and Shelley: The Making of a Metaphorical Body," Studies in Romanticism 29 (Spring 1990). 
must be structurally similar. ${ }^{2}$ By this token, the attempt of romantic hermeneutics to reverse the negativity of the text at the level of expression by a reading that returns to the original 'perception' behind expression or by one that applies art to knowledge and use seems highly problematic. For although psychological and applicative reading are different from grammatical reading and from the rhetorical reading that has replaced exegesis in an era that no longer regards expression as stable, their very real qualitative difference is, so to speak, constituted on the trace of their structural similarity. To read on the psychological and applicative as well as the rhetorical level is to restore the affective (or emotive) and the referential power of literature. But that is not to suggest that emotion and action are less complex than verbal language, more easily decipherable, more self-identical.

Shelley concedes as much when he describes the performance of the fourth act as a "perpetual Orphic song, / Which rules with Daedal harmony a throng / Of thoughts and forms, which else senseless and shapeless were" (IV. 415-17). Action, whether it be acting out something in the theater of the mind or acting in the stage of the world, is here seen as a will to power, a surface orientation given to a state of mind more complex and conflicting than we represent it as being. It involves a process of substitution and abstraction by which we make one act represent a differential complex of motives. That all performative readings are thus deconstructible is something that Shelley in Prometheus Unbound considers as a philosophical problem but brackets as an experiential problem. How to preserve the psychological and applicative dimension of literature without engaging in an abstract compartmentalization of the practical and the metaphysical is thus the problem that he must work through in The Triumph of Life. For the use of drama in Prometheus has two rather different implications, both of which a phenomenology of disarticulation must comprehend as symbiotically related. In moving from the first scene of reading, which lyricizes dialogue by creating a unity between two different voices, to the second scene, which focuses on dialogue as difference, Shelley recognizes dialogue and drama as the dissemination of unitary vision. On the other hand, drama is not quite the same thing as dialogue, nor is the play reducible to what happens in the Cave of Demogorgon. For theater also disseminates vision in a quite different sense: it produces ideas, materializes them on the stage of the world.

In Prometheus Shelley elides the difference within drama, subsuming one form of dissemination into the other. In The Triumph of Life he

\footnotetext{
2Shelley, A Defence of Poetry, in John E. Jordan, ed., A Defence of Poetry and The Four Ages of Poetry (Indianapolis: Bobbs-Merrill, 1965), p. $31 \mathrm{n}$.
} 
returns to this aporia to ask whether language can produce meaning if its very process effaces it. The Car of Life with its procession of historical figures seems to represent the language of events as a chain of substitutions: one figure merely taking the place of another in a way that will make us, too, into figures if we follow Rousseau's injunction to try and enact meaning within the text (ll. $30_{5}-8, S P P$ ). These figures are repeatedly described as shadows or phantoms, as if the vision being rolled on our brains is of the twilight of the idols, the fading of the subject (ll. $25^{1}$, $253,289,487-88,534, S P P)$. But they are also the "mighty phantoms of an elder day" (l. 253, SPP), traces of a cultural grammatology in which the erasure of figures remains entangled in their survival. Turning toward the past instead of the future, the poem asks us to read these traces: to become mirrors of the gigantic shadows that the past still casts on the present even as it is being effaced.

Reinscribing Difference: Speech, Dialogue, and Dia-logos

At first sight, The Triumph of Life seems simply to dismantle the assumptions of Prometheus Unbound. Not only does it recapitulate negatively such motifs as the chariot of the hour; as a fragment it aborts meaning, where as theater Prometheus produced it. No analysis of the poem can now ignore the seminal essay by Paul de Man that sees the diegetic level of the text as preempting all attempts to approach it thematically. All interpretations of the poem hitherto have assumed that it 'says' something, that it has a content other than the processes of its own language. Such interpretations would include those of Bloom and Woodman, who make the poem didactic or apocalyptic, viewing it as a critique of Rousseau for having been seduced by nature and perhaps as a rejection of life in the manner of Adonais. But they would also include more recent ones like my own in Dark Interpreter, which deconstructs the binary oppositions crucial to earlier readings only to make the poem's indeterminacy the regenerative prelude to what it does not quite succeed in saying. My reading elides the fragmentary status of the poem and provides a hermeneutic completion for it by arguing that it is in the process of rehabilitating Rousseau. His shifting view of himself is thus explained by the fact that he is in transit from the Platonic repudiation of the phenomenal world associated with the sacred few to an existential embrace of life in which activity is its own Sisyphean reward. ${ }^{3}$ Describing

${ }^{3}$ Harold Bloom, Shelley's Mythmaking (1959; rpt. Ithaca, N.Y.: Cornell University Press, 1969), pp. 220-75; Ross Woodman, The Apocalyptic Vision in the Poetry of Shelley (Toronto: University of Toronto Press, 1964), pp. 180-98. Woodman's argument is characteristic of 
a range of interpretations that either view the movement of the poem as negative (a rejection of life) or positive (a discarding of old positions in order to work through to new ones), de Man dismisses them as captive to an idealizing genetic metaphor, which insists that there is psychological growth in the poem, that it moves toward some insight. Instead, he shifts his attention to its rhetoric, which he characterizes in terms of erasure, disfiguration, the syntax tying itself into a knot. In figuring the poem as a scene of reading in the larger setting of Western culture, de Man sees it as challenging the hermeneutic foundations of that culture, which represents reading as the recovery of something meaningful and its application to the life of the reader, and which thus places texts as spots of time to which we can repair for increased self-understanding. ${ }^{4}$

The power of de Man's essay lies in his exposure of the ways in which previous readings have made something out of the poem without attending to its most pervasive feature: the status of a language unable either to state or to perform anything that is not already different from itself. Yet it remains to be seen whether the poem's lack of 'identity' renders it 'unreadable' or brings into being a reconception of the supplement of reading. For one thing, de Man (as he would be the first to admit) has provided a 'reading,' by making form take the place of a vanishing content through a hypostasis of the poem's method. Or to put it differently, even this text, which asks to be approached diegetically rather than mimetically, has a referent, that referent being the process of the poem itself. If we grant that de Man has provided a reading, the issue raised by his concept of unreadability is not whether the poem has any meaning, but whether the way it foregrounds its own discourse invalidates its power to create something meaningful. Put differently, the issue is whether the poem still permits reading as it is understood by the developing tradition of hermeneutics discussed in this book. The greatest challenge to answering this question affirmatively is not the language of the posthumously printed text but the tangle of the manuscript in which Shelley himself left the poem. De Man does not refer to the manuscript except in passing, but it plays an important symbolic role in his reading, the mutilated text becoming a disfiguration of any attempt to read Shelley or to read Shelley as a paradigm of romanticism. As a synecdoche for Shelley's drowned body, which is inscribed in its last page, the manuscript thwarts our attempts to incorporate the scandal of disfiguration into literary history. ${ }^{5}$ We could speculate that if de Man

a certain phase of romantic criticism but is unlikely to represent his view now. Tilottama Rajan, Dark Interpreter: The Discourse of Romanticism (Ithaca, N.Y.: Cornell University Press, 1980), pp. 58-71.

4Paul de Man, "Shelley Disfigured," in Harold Bloom, Paul de Man, et al., Deconstruction and Criticism (New York: Continuum, 1979), pp. 39-74. See esp. pp. 39-42, 44-46.

${ }^{5}$ Ibid., p. 67. 
had discussed its details, it would have become the trace left by an irreducible aporia at the heart of language and the site of our submission to that aporia. Thus, any attempt to re-vision the poem's discourse must deal not only with its language but also with the intervention made by the manuscript in the institutional structures of literary criticism.

Our discussion of the poem will focus on how it functions: on its repetitions, its syntax, and on its foregrounding of speech over writing, as elements that create differences within the rhetoric of erasure, so that disfiguration is not just the effacement of figures but also the production of new figures. In many ways this discussion subsumes my own previous analysis, which saw Shelley's poem as generated by a process of selfrevision. Crucial to that analysis was the unsettling of a pattern of binary oppositions by which earlier readings had schematized the poem so as to criticize Rousseau for participating in life. Such oppositions included those between the sacred few and the multitude that was not wise enough to avoid life (ll. 128-37, SPP); between the bards of elder time and Rousseau himself, whose lack of distance from the world he wanted to change resulted in his infecting his audience with his own misery (ll. 274-81, SPP); and most importantly between the two shapes, the shape all light generated by the spark with which heaven initially lit Rousseau's spirit, and the shape in the car that replaced it when he put on the "disguise" of life. There is no question that the text is profoundly ambivalent about "Life," and that that ambivalence disrupts not only the earlier view that the poem was written by a 'Platonic' rather than 'radical' Shelley, ${ }^{6}$ but also the recent emphasis on its semiotic nihilism. But instead of embedding that ambivalence in a genetic narrative that absorbs aporia into the dialectic of Rousseau's (and the poet's) maturation, I will assume that my earlier reading is a heuristic construction. It must therefore be reinscribed in the text that generates it, and is present in the text only as a trace and not as what Godwin called the poem's 'tendency.' The details of this reading are less important than the linguistic processes that make it possible, while also generating the kind of reading provided by de Man. And these processes, too complex to be summed up in the term 'effacement, ${ }^{7}$ are in some form intrinsic to all poetic narrative, even though they may be foregrounded in this poem. But the details of the reading are also not unimportant. For the eschewing of the thematic in favor of the figural elides both the possibility that the nature of the figural may be altered by what we pick out as being (dis)figured, and the recognition that much Yale poststructuralism takes form as a thematics

6I borrow this distinction from Milton Wilson, Shelley's Later Poetry: A Study of his Prophetic Imagination (New York: Columbia University Press, 1959), pp. 176-77.

${ }^{7}$ For a discussion of the concepts of face and effacement, see de Man, "Shelley Disfigured," p. 46 . 
of figures: in other words, as a reading that can be challenged thematically as well as linguistically.

For the sake of convenience, we can divide the poem into three sections: an opening segment in which 'Shelley' falls asleep in a transfigured natural landscape only to witness its transformation into the dismal scene of the procession; a dialogue between him and Rousseau in which the latter describes in detail the significance of the same procession; and a dream narrative that describes an experience parallel to 'Shelley's' initial experience, namely, the transformation of the shape all light that Rousseau conceived at the moment of his creative birth into the shape in the chariot with its attendant procession. On the most obvious level the poem tells a characteristic romantic story about the collapse of illusion. Its return (three times) to the procession emphasizes in an emblematic way the chariot that erases hope and the chain of historical figures without origin or end. But the fact that the poem's title does not specify whose triumph it details (that of Life over humankind, or the triumph that is life, the triumph of surviving) suggests that it cannot simply be reduced to its most traumatic images: the car that wipes out what preceded it as the shape obliterates Rousseau, and the procession of disfigured dancers who follow it. These are in turn the figures that de Man uses to represent figuration and must be set against other images whose presence suggests that language is a form of the unconscious, and that so far we have only succeeded in representing, not in understanding it. Among these other images are the car's "creative ray" (l. 533, $S P P$ ); the association of life with dance, music, and embroidery (ll. 98, 110, 142, 448, SPP); and the image of life as a cleaving apart that sculpts the "marble brow of youth," allowing form to emerge only through disfiguration (l. 523, SPP).

We can locate the poem's indeterminacy partly in its repetitions: the repetition of the procession; the repetition of 'Shelley' as Rousseau; the temporal repetition of Rousseau's life in the form of a retrospective narration; and finally the repetition of Rousseau's attempt to understand the core experience of the transformation of something beautiful into something hideous in the discursive form of a conversation with 'Shelley,' and in the symbolic form of a dream sequence unimpeded by conceptual filters. Because the poem is a dream, its repetitive organization suggests an incomplete attempt at mastery: an attempt that we repeat each time we interpret the poem. Blocking progress, the figure of reading as repetition halts any attempt at the teleological completion of the poem. But though repetition may be intended to confirm trauma, it also allows reading-again to become the production of differences. We do not repeat something in different words if we mean to say exactly the same thing. Repetition implies the insufficiency of what was said: we 
repeat because there is still something more to be said, something more to be read in the political unconscious whose shadows are mirrored in this poem. Moreover, the attempt to understand the poem's core experience is repeated by Rousseau at different stages of his life: as the young man who experiences the transformation of the shape, as the older man who remembers it, and as the subject in dialogue with Shelley, in conversation with a future that discloses new perspectives to him even as it seems to close itself against him. It is repeated by 'Shelley,' both as the autonomously later subject who sees the procession, and then as the subject in dialogue with the past who re-views the procession in his conversation with Rousseau. By repeating itself at different points on a personal and on a historical axis, by allowing these axes to intersect in different ways, the poem generates more than one perspective from which we can view it and gives to the repetition that is reading a complex and still unfinished historical dimension.

The Triumph is organized so as to foreground repetition on a narrative level and so as to make it a figure for understanding. But the poem's structure simply raises to a level of self-consciousness what is a feature of all extensive utterance: namely, a tendency to repeat along different axes, to illustrate concepts through figures or fables, or conversely to reduce symbols or narratives to conceptual paraphrases. We become aware of how the poem is complicated by such micrological repetitions in the very first segment. For the most part 'Shelley' describes the followers of the car with condescension and takes the view that their error is involvement in life. But his argument is constantly disarticulated by the figures he uses to convey it, this despite his attachment to similes, which maintain a formal commitment to the exact equivalence of image and referent. For instance, in dismissing the procession he tells us that it includes:

All but the sacred few who could not tame Their spirits to the Conqueror, but as soon As they had touched the world with living flame

Fled back like eagles to their native noon.

(ll. 128-31, SPP)

This binary opposition between the multitude who are captivated by life and those who see through it is more explicitly unsettled in Rousseau's account of the procession. But even here it is undermined by the description of the sacred few as "fleeing," Thel-like, from the generative world, and by the fact that the noon of transphenomenal vision that they embrace only seems to be outside the temporal cycle. And on the other hand, the dancers in the procession are described with an energy and 
vitality that belies their portrayal as part of a sad pageantry. One example is the account of how they are destroyed by their own desire for life. To begin with, they are described as moths attracted by the light (ll. 153$54, S P P)$, but then they are paralleled to

... two clouds into one vale impelled

That shake the mountains when their lightnings mingle

And die in rain.

$$
\text { (ll. } 155-57, S P P \text { ) }
$$

The second simile displaces the first by continuing its emphasis on selfdestruction but making this a generative rather than a futile activity: productive of rain that will fertilize the land. This is only one example of how a statement is unraveled by its multiplied figurative repetition and how the process of articulation generates new perceptions about the car's followers which refigure the pageant of error as a vital and Dionysiac dance.

The dialogue of text and subtext in 'Shelley's' monologue generates quite naturally his repetition of himself in the person of Rousseau and his placing of himself in a dialogical setting. Rousseau seems at first to confirm 'Shelley's' rejection of life. But a measure of how unsettled his position is is the discrepancy between his initial advice to 'Shelley,' "Forbear / To join the dance" (ll. 188-89, SPP), and his later suggestion that involvement is the only means to understand it:

"But follow thou, and from spectator turn

Actor or victim in this wretchedness

"And what thou wouldst be taught I then may learn From thee.-

(ll. $305^{-8, S P P)}$

Nor does Rousseau's account of the procession simply duplicate 'Shelley's,' for the participants are now named and individualized, which makes it difficult to dismiss them as an anonymous multitude. The roll call of names, moreover, includes all the great figures of Western culture and leaves us wondering who the "few" who have avoided life might be. Bacon, compared in the manuscript to an eagle and thus imagistically linked to the sacred few, ${ }^{8}$ is in the procession, as is Napoleon with his

8References to the manuscript are to Donald Reiman, ed., "The Triumph of Life: A Facsimile of Shelley's Holograph Draft," The Bodleian Shelley Manuscripts: A Facsimile Edition, with Full Transcriptions and Scholarly Apparatus, vol. I (New York: Garland, 1986). 
"eagle's pinion" (l. 222, SPP). But it now seems to be Bacon's error that like the sacred few he wanted more than the phenomenal world and tried to force "The Proteus shape of Nature" to yield him a truth (ll. 269-71, SPP). Socrates, once exempt from the procession, seems to enter it vicariously through Plato, who "Expiates the joy and woe his master knew not" (l. 255, SPP), as if Plato's very inferiority is a greater knowledge and Socrates' superiority a sin. Plato, moreover, has been conquered by "love" (l. 258, SPP), not something for which we can criticize him, especially since Socrates in avoiding woe was also ignorant of joy. Though repeating 'Shelley's' account of the procession, Rousseau's is actually quite different. One could do an extensive thematic analysis of the section, showing how as he speaks, Rousseau creates a space in which he can think and in which he can unravel not only his earlier radicalism but also his present condemnation of himself for having entered life. It is specifically the diacritical nature of dialogue which causes it to unsettle and generate penumbral positions, for the presence of the other person makes us recognize that we are other than what we are, and yet that we are not the other or the other's perception of us. But my concern is also with a characteristic linguistic feature of the poem, which complicates the movement of syntactic erasure. I have in mind the way in which negative statements are constituted on the trace of positive ones, or to be more precise, the way in which negative statements are in their turn negated, so as to produce the trace of something positive, though only as a shadow that futurity casts upon the present.

We notice how of ten the trace of self-assertion is masked within Rousseau's statement that he is not something, or to put it differently, how often erasure generates a construction, both in terms of syntax and in terms of the syntax of identity and action. A significant example is the passage on the bards of elder time, which has been edited differently by Mary Shelley and by Donald Reiman, thus raising the ancillary question of how the state of the manuscript affects our attempts to (de)construct the poem's significance. Mary Shelley's version, as Reiman's transcription indicates, was deleted, though less definitively than he implies. However, I begin with it partly because it was the text that most people read until Reiman published his reading text of the poem in the 1977 Norton critical edition. Moreover, given the unfinished state of this poem, in which convenient deletions are not always made and final intentions are hard to extract, no deletion can be sufficiently absolute to counteract the material force of the manuscript as a palimpsest in which the trace of an earlier version survives in emendations that repeat and displace it. For instance: 
"See the great bards of elder time, who quelled

"The passions which they sung, as by their strain May well be known: their living melody

Tempers its own contagion to the vein

"Of those who are infected with it-I

Have suffered what I wrote, or viler pain!

And so my words have seeds of misery-

"Even as the deeds of others, not as theirs."

And then he pointed to a company.

$$
\text { (ll. } 274-82)^{9}
$$

Grammatically, these lines are destabilized by a curious tension between Rousseau's statement that he is not the equal of the bards and the selfassertive position of the personal pronoun in 1.278 , which prevents them from neatly settling into a representation of Rousseau as inferior. Entangled in the next line (279) is a sense that Rousseau has suffered more than the bards and thus is not as great as them, but also has lived at a greater intensity. Even more interesting are lines $280-81$. They castigate Rousseau for writing words that have destructive consequences in the world of action and therefore are "not as theirs," not like the tranquilizing words of the bards. Yet this does not exhaust the meaning of "not as theirs," which dangles oddly at the end of the line, attempting to erase the forceful impression of what Rousseau has done by reintroducing the bards in a rather unprepossessing and pronominal way as something that Rousseau is not, through a word ("theirs") that has no clear antecedent in something actually achieved by the bards. To elaborate, it is not clear whether "theirs" refers to the words of the bards or to their deeds, which are not "as the deeds of others." And at this point we begin to recognize that perhaps the bards have no deeds, but only words, and that in this they are not like Rousseau, whose words reach out beyond the monastery of language. My point is that at no place in Rousseau's discourse are grammar and statement fully adequate to each other, so that the grammar paradoxically deconstructs the poem's logic of erasure, leaving a residue, a trace, that makes it different from itself.

What emerges from this analysis is that although the text is constantly erasing itself, that process is by no means unidirectional. In attempting to deny the value of his own work, Rousseau is unable to construct the bards as a positive counterpoint and instead reconstructs their position

${ }^{9}$ Mary Shelley's version is reprinted in The Complete Poetical Works of Percy Bysshe Shelley, ed. Thomas Hutchinson (London: Oxford University Press, 1905). 
by telling us what it is not. The result of this double negation is to efface his self-rejection, but without immediately representing himself in a positive light. The double negation dilutes the force of the binary opposition by which Rousseau tries to measure his failure against the norm furnished by the bards. But on the other hand, the fact that his rehabilitation is initially no more than a syntactic trace, and the fact that his assertion of his own achievement is deferred to a passage some stanzas later (ll. 292-95, $S P P$ ) gives this self-assertion a tentative and supplementary quality. The vindication of Rousseau also leaves out something - which is perhaps why the manuscript could not be finished. We will return at the end of this chapter to the hermeneutic problems posed by the manuscript. But for the present it is worth noting that the line about which there is disagreement exists in three manuscript states: an 'original' state (already a reading that jumps from f. 33 r. to f. $33^{\mathrm{v}}$., omitting 'irrelevant' material) the version chosen by Mary Shelley, and the version (by no means final) chosen by Reiman. Set in between the two other versions of the line, the anxious negativity of the one we have just analyzed becomes all the more interesting:

1. Thus have my words been seeds of misery-

Even as the deeds of others-even as theirs

And then he pointed to a company

[original; italics mine]

2. "And so my words have seeds of misery-

"Even as the deeds of others, not as theirs."

And then he pointed to a company,

[Mary Shelley's version]

3. "And so my words were seeds of misery-

Even as the deeds of others."-"Not as theirs,"

I said-he pointed to a company

[Reimaṇ’s version]

Reiman's version, to which we will return, breaks up line 281 and assigns the second half to 'Shelley' instead of to Rousseau (a questionable attribution, since the manuscript at no point uses quotation marks). In the 'original' version, (reconstructed by undoing Shelley's cancellations), it seems that Rousseau speaks the entire line and that its meaning is relatively straightforward: his words sow misery, like the deeds of others, "even as" the deeds of those to whom he then points. In the intermediate version Rousseau reassigns the antecedent of "theirs" from the company of despots to the bards: his words are like the deeds of others, 
and not as theirs (the words [?] of the bards [?]). In Reiman's version, which does not definitively replace the second one, ${ }^{10}$ the poem once again avoids the double negative. The words "not as theirs" are reassigned so that they neither support nor confuse the opposition between Rousseau and the bards. Rather, they prepare the way for Rousseau's later distinction between creative and destructive forms of power by having 'Shelley' differentiate Rousseau's verbal deeds from the actions of the despots: his deeds are "Not as theirs," not like the atrocities they commit. Somewhere in between an opposition that devalues Rousseau and an uncharacteristic response by 'Shelley' that rehabilitates him is Mary Shelley's version, a version that makes the positive a trace within the negative. In this interstice in Rousseau's speech, he emerges as the difference between a self-rejection in which he cannot find identity and a self-assertion whose lack of finality is evident in the fact that the poem continues, as if this is just one more figure cast on the "fragile glass" (l. $247, S P P$ ) in which identity (dis)appears:

- "Their power was given

But to destroy," replied the leader-"I

Am one of those who have created, even

"If it be but a world of agony."-

(ll. 292-95, SPP)

The self-displacing energies of speech are equally evident in Reiman's version of the passage, which seems at first to invalidate our reading. Removing the awkward phrase "not as theirs" from Rousseau's speech, Reiman tidies up what Rousseau says and allows it the neatness of a straightforward opposition. But the new version is no simpler, because the referent of what is now 'Shelley's' half-line intervention is less clear than we have made it seem, depending as it does on whether we connect the phrase to what precedes or to what follows it. We can take the antecedent of "theirs" to be the bards, in which case 'Shelley' seems to be confirming Rousseau's self-repudiation by adding to the latter's claim that his words are like vicious deeds a clarification that tells us that Rousseau's words are indeed unlike the words of the bards: "Not as theirs." Alternatively, we can take the statement as referring to the despots 'Shelley' proceeds to list, in which case he is dissenting from Rousseau's self-condemnation to observe that Rousseau's verbal deeds have not produced the misery created by tyrants and demagogues. It seems logical to connect 'Shelley's' intervention to what precedes it and to see him as condemning Rousseau, because that is what 'he' usually does.

${ }^{10}$ See my discussion later in this chapter. 
Moreover, it is Rousseau (not 'Shelley') who points to Caesar and Constantine, so that the list of despots does not seem to come as an illustration of 'Shelley's' statement. On the other hand, it is just as logical to connect 'Shelley's' intervention to what follows it, because it is after all he who recognizes tyranny for what it is, thus enabling Rousseau to make his subsequent distinction between creative and destructive power. ${ }^{11}$ At issue is whether 'Shelley' repudiates or rehabilitates Rousseau, and the problem cannot be resolved because he seems to do both. Diverging from Mary Shelley's version in the assignment of words to characters, Reiman's version differs only in extending the entanglement of positive and negative from Rousseau to 'Shelley.' In the course of the dialogue Rousseau moves from self-rejection to a self-justification that, being an equal and opposite reaction, has no final authority. In his brief intervention, and in the silent meditation on tyranny that follows it, 'Shelley' exhibits a similar ambivalence produced, it would seem, by the tendency of extended discourse (whether silent or verbal) to revive the traces of what it does not say.

If the sense of poetry as difference emerges linguistically at the level of the poem's grammar and generically from its dialogue form, it is also presented mythopoeically in the scene of Rousseau's creative birth, where he imagines the shape all light that later becomes the destructive shape in the car. The background in which the shape appears is a complex intertexture of light and shadow, shadow and substance:

\section{"but all the place}

"Was filled with many sounds woven into one Oblivious melody."

$$
\text { (ll. } 339-41, S P P \text { ) }
$$

Though this is apparently a scene of paradisal origins, oblivion alone makes us ignore that it is woven of many elements. Of particular interest throughout the poem are the figures of music and dance, but specifically in this passage of melody, for herein lies the deconstruction of Rousseau's oblivious perception of unity. We may think of Nietzsche's use of music in The Birth of Tragedy to symbolize the originary difference that is the ground of all systems of representation. But Shelley himself discusses music in the Defence, in terms of a vertical/referential axis and a horizontal/associative axis, which at another point he attributes separately to poetry and all the other arts, respectively. Harmony is the internal adjustment of sounds to their referents, but melody is the un-

${ }^{11}$ This is how Reiman reads the passage in his notes to the Norton critical edition (SPP, p. $4^{6} 3$ n.). 
schematized play of external and internal impressions over the mind (SPP, p. 48o), a perpetual motion of impressions that develop relations among each other that interpose between conception and expression. Hume, similarly, had linked music to the interpresence of apparently separate elements within a syntagmatic chain. In discussing the passions, he compares the mind to a stringed instrument "where, after each stroke, the vibrations still retain some sound. . . Each stroke will not produce a clear and distinct note of passion, but the one passion will always be mixed . . . with the other." 12 Rousseau's error, if we can speak of one, is to create a unitary form (a shape all light) out of this differential ground through an act of Orphic will. Or rather, since the shape seems autonomously generated by a combination of light and optics-by a process at once perceptual and natural-, his error is to isolate the shape from its spatial and temporal context. For the apparently single shape emerges from a background of difference, as a moment in a process that consolidates and fixes an impression only to complicate it, threading "all the forest maze / With winding paths of emerald fire" (ll. $347-48, S P P)$ :

\section{... "there stood}

"Amid the sun, as he amid the blaze

Of his own glory, on the vibrating

Floor of the fountain, paved with flashing rays,

"A shape all light, which with one hand did fling

Dew on the earth, as if she were the Dawn."

$$
\text { (1l. } 34^{8-53}, S P P \text { ) }
$$

It seems clear that what is described here is the making of a figure through a process of substitution and displacement. To begin with, it is not the sun that we see, but the sun's image in a body of water that is confusingly a well or a fountain, in other words, the sun as constituted by

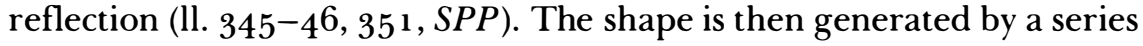
of synecdoches in which a diffuse and formless radiance imaged in the water is represented by an anthropomorphized sun described as "he," which in turn is represented by an inner, more focused female shape, metaphorically identified as the dawn, and as the dawn of a new era. There is indeed nothing unusual about a romantic poem's drawing attention to its construction of a myth. But here the process by which a myth is traced from its genesis in a moving army of metaphors and

\footnotetext{
${ }^{12}$ David Hume, "Dissertation on the Passions," quoted by Engell, The Creative Imagination: Enlightenment to Romanticism (Cambridge, Mass.: Harvard University Press, 1981), p. 54 .
} 
metonymies to its misprision as truth is presented as a hypnotism. Long before Rousseau explicitly perceives that the shape is not as simple as he takes it to be, the destructive effects of its formation are described:

"And still her feet, no less than the sweet tune To which they moved, seemed as they moved, to blot The thoughts of him who gazed on them, and soon

"All that was seemed as if it had been not, As if the gazer's mind was strewn beneath Her feet like embers, and she, thought by thought,

"Trampled its fires into the dust of death." (ll. $382-88, S P P$ )

As Rousseau allows himself to be captivated by the unitary shape that momentarily forms itself out of the play of differences, the ground of his creativity is erased. The sparks of his mind (1. 201, SPP), Shelley's image in the Defence for thought as a productivity, are trampled out as one idea is made to represent a differential complex of ideas and "All that was seemed as if it had been not." For as long as the mind is inhabited by a variety of different thoughts, as long as we remain aware that the dominant thought is constituted on the trace of what it does not say, the mind remains in Shelley's image both here and in the Defence a 'fountain' (l. $\left.35^{1}, S P P\right)$, or more precisely a source of elements between which we can form new relations. Thus the creative oblivion Rousseau suffers in these lines is not something done by the shape to him, but rather something that he does to himself as he yields to the impossible desire to create a unity out of multeity. For the shape, as light, is not a fixed form but a moving army of particles. She is, moreover, a dancer, dancing "i' the wind where eagle never flew" (1. $381, S P P$ ), beyond the grasp of those who reject the differential flux of life for the native noon of single rather than manifold vision. Those who will survive the dance of language dance with her, as Rousseau comes to do and enjoins Shelley to do. Those who abstract a single form from the dance, as Rousseau once did, find the spark of their creativity killed.

Even after his first encounter with the shape of his own mind ends with its disintegration, Rousseau's sense of what constitutes truth remains simple. Thus the unitary construction of the shape as 'all light' is now replaced with an equally partial perception of it as entirely destructive. Dimly, however, he is beginning to grow aware that the figures the mind constructs, whether negative or positive, contain the trace of their own difference from themselves: 
"So knew I in that light's severe excess The presence of that shape which on the stream Moved, ..."

"So did that shape its obscure tenour keep

"Beside my path, as silent as a ghost."

$$
\text { (ll. } 424-33, S P P)
$$

On a diegetic level, then, the poem, while essentially deconstructive, does not present a process of pure erasure. Rather, it shows us how the power of deconstruction at the heart of language actually produces meaning. The image of erasure crucial to de Man's analysis, ${ }^{13}$ of the waves perpetually erasing the tracks of wolves and deer on the sand, is Rousseau's image, used with reference to what is chronologically the earliest segment of his life, to describe his initial sense of vertigo at the destruction of old positions (ll. 405-410, $S P P$ ). A variant of it turns up in Rousseau's dialogue with Shelley in the present, namely, the image of figures painted on a bubble (ll. 248-51, SPP). But if indeed the words are his, ${ }^{14}$ he uses this image in response to a comment by Shelley, which he qualifies by pointing out that if cultural heroes are merely historical figures, this does not make them identical, erasible, reducible one to the other. Plato, he tells us, "Expiates the joy and woe his master knew not" and is uniquely different from Socrates. The poem does, to be sure, operate in terms of grammatical and conceptual displacements. But if this were purely a matter of erasure, we would feel a sense of loss at Rousseau's inability to rest with his rejection of the phenomenal world, instead of feeling that the presence of other responses creates openings in the poem.

Paradoxically, then, The Triumph of Life is profoundly committed to the power of LOGOS, or rather DIA-LOGOS. If it deconstructs writing as an enduring monument by refusing to let Rousseau rest in peace, it valorizes speech as closer to a presence-as-difference. As writer, Rousseau had used the power of the published book as a means to fix meaning and achieve canonical status. But by the same token he was dead, catalogued like Adonais in the abode where the eternal are. Paradoxically, it is because 'Shelley' does not let him rest but deconstructs him that he comes to life, for to be deconstructed is to be read, and Rousseau is at least read, where 'Adonais' in some sense is killed with reverence. But more importantly it is through the power of speech that Rousseau returns to life, because until he speaks, he is simply a root in the hillside.

${ }^{13}$ De Man, "Shelley Disfigured," pp. 45-46.

${ }^{14}$ Since there are no quotation marks in the manuscript, it does not follow that Rousseau speaks these words. It is just as possible that his part of the dialogue begins at l. $25^{2}$. 
The dialectic of author and reader, as Shelley dramatizes it here, is a complex one, which transforms writing into speech through a process in which the reader deconstructs the writer, but in which the writer also speaks back and in some sense deconstructs the reader. Two things occur in the extended interchange between 'Shelley' and Rousseau. Rousseau loses his authority over his own words in entering the circuit of reading: they can be appropriated in different ways by different readers, such dissemination being the price of the communication for which Shelley uses the image of the spark and of the acorn that contains all future oaks (SPP, p. 50o). But 'Shelley,' too, loses his authority over his reading, which becomes part of the differential process of speech between writer and reader. He becomes what we might describe as a lector rather than a reader, following Barthes' distinction between the author who controls the circulation of meaning and the scriptor who is a function of his own language. ${ }^{15}$ Though 'Shelley' does not recognize his changed status and does not speak again after Rousseau's account of his dream, such a shift seems implicit in the fact that Percy Shelley takes both author and reader out of contexts that may be thought to exist outside language (death in Rousseau's case, ordinary life in 'Shelley's'), and places them in a world of language.

The Triumph of Life is thus committed to speech and reading, to the human participation in the dance of words. Shelley's poem is characteristically romantic in actually valorizing speech, but speech (whether fictional, psychological, or political) is something very different from what Derrida criticizes in his distinction between speech (equated with a language that is self-identical) and writing (equated with difference and the loss of presence). For these terms Shelley substitutes an opposition between writing (equated with codification) and speech (equated with presence, but also difference). The written book offers a certain security, as something that confers on words the finality, recognition, and also the complacency of publication. But speech, which Rousseau engages in when he leaves the archives to encounter 'Shelley,' exposes and also revitalizes his words by placing them in a dialogical relationship with an other or with a world that dismantles and reconstitutes them. Nor is this view of speech confined to Shelley, for the renewed interest in Platonic dialogue evident in eighteenth-century British philosophy, in the hermeneutics of Schleiermacher and others, and in forms like the conversation poem, is at least potentially an interest in speech-as-difference: in speech as superior to writing because it is more fluid and indeterminate. Similarly, the poem actually valorizes reading. In some sense it is, as de

${ }^{15}$ Roland Barthes, Image, Music, Text, trans. Stephen Heath (New York: Hill and Wang, 1977), pp. $145^{-46 .}$ 
Man suggests, a deconstruction of reading, because it presents language as a process of repetitive expansion that unreads itself and therefore unreads any attempt at unitary interpretation. But this is only to say that it deconstructs the kind of allegorical reading practiced by the character 'Shelley,' who tries to establish a one-to-one correspondence between figure and referent, to read the scene he witnesses into a book and out of his life. It is no accident that 'Shelley' uses simile rather than metaphor, that he describes the dance as a "just similitude" (1. 117, SPP), and that he tries to construe it in terms of literary conventions such as the medieval dream-vision and the Petrarchan triumph that will help him to label its characters and themes (ll. 40, 118, 176, SPP). But in a deeper sense the poem can be seen as developing a complex symbiosis between reading and deconstruction. As 'Shelley' reads Rousseau and more importantly as Rousseau reads himself, narrating the growth of his mind not to arrange and monumentalize his past like Wordsworth in The Prelude but to reread it, he unweaves his past self in such a way that his rereading unreads itself and creates a further language within language. It is, moreover, the fact that we can discover ever new relations within the poem that keeps us and future generations reading it. It is, of course, a far cry from this defense of reading to the one constructed by a traditional hermeneutics that sought to recover the original meaning of the text. We may discover how the poem functions as process but we do not discover its original meaning, any more than Rousseau, in recounting his past, is able to discover the original meaning of his life. Rather, we appropriate the poem to our own experience and create something meaningful out of it by participating in it, by becoming actors rather than spectators, and teaching the text what we would learn from it.

The Fading of Philology: The Manuscript and the Subject of Reading

But what does it mean to read heuristically and to realize that what we perceive in the text is partly what we create through reading? In the Defence Shelley speaks as though dissemination is a plenitude. But in this poem, which reduplicates the earlier theory in a glass darkly, the process is more recursive. Any reading we construct of Rousseau or of the text must be inscribed in its own differences: in the difference of our interpretation from a manuscript that will always in some way contradict what we attribute to it. No interpretation can now proceed without taking account of the original, which is unusually tangled, and in such a way that we wonder whether it is as it is because of the accident of Shelley's death or because of something in it that resists completion in the form of a conventional poem. The state of the manuscript raises fundamental 
questions about the status of the reading subject, about the nature of textual origins, and about the relationship between a printed text accessible to technical reading and a manuscript that encourages psychological reading, but in a radically intertextual way.

To read this manuscript, in contrast to surviving manuscripts of Hellas or Prometheus Unbound, is to experience an enormous gulf between its chaos and the iconic clarity of the printed text. It is also to reassess our very conception of what Schleiermacher called the indefinite thought process that precedes the finished thought complex. That The Triumph survives only in manuscript may be an accident. But the accident is part of the text's history and produces that history as a kind of mirror-stage on which the identity of editing, of philology, and of reading is projected and broken. We could do an extensive study of the points at which editors have (necessarily) cut, bridged, or otherwise amended the manuscript to make a readable text out of it. We will, however, confine ourselves to two recurrent aporias in the manuscript: the problem of (un)canceled passages and that of punctuation.

Not surprisingly, there is much more in the manuscript than appears in the printed text. Indeed, the discrepancy is so severe that Reiman has recently found it necessary to call into question his entire editorial activity by going beyond the re-edited text with notes on the manuscript that he published in $1965,{ }^{16}$ and providing a facsimile of the manuscript itself with a full transcription. From the manuscript it is evident that editors have played a role in producing the poem not entirely dissimilar from that of Ezra Pound in relation to The Waste Land. From Mary Shelley's to Reiman's, reading texts choose one version of a phrase or a line, where the alternatives are not clearly canceled out in the manuscript, and more of ten they shape a stanza out of a passage that contains uncanceled bits of lines that are surplus to the terza rima form. If the reading text facilitates coherent reading(s) of the poem, the publication of the manuscript compels us to go beyond a technical to a psychological reading, in which we recover the subtextual and collateral thoughts that keep deferring Shelley's attempt to give the play of language a direction. The manuscript, in other words, encourages us to read the poem as a palimpsest of traces, as the site of its own constant displacement. One of its more interesting features is the way it introduces alternatives that are sometimes quite radically opposed to each other. In general, Shelley chooses between these alternatives, but when he does so, the unfinished and self-canceling nature of the manuscript tends to make us erase the cancellations and see his choices as constructed on the trace of what they 
do not say. Close to the beginning of the poem as it is printed, 'Shelley' describes the multitude who follow the chariot and comments that "none seemed to know / Whither he went, or whence he came" (ll. 47-48, $S P P)$. But in the manuscript Shelley writes and then crosses out the line "And by their motions they appeared to know." On the question of whether the multitude are unthinking victims of life or enter its dance knowing full well what they are doing depends the further problem of whether Rousseau's participation in life is an error or an existential commitment. And at least at one point Shelley sees the question as yielding completely different answers.

Likewise, in the passage on the sacred few it seems that Shelley was uncertain whether the few "were there" in the procession or were "neither mid the mighty captives seen." In completing an incomplete revision, Reiman erases what is in effect an aporia. ${ }^{17}$ This pattern of opposed alternatives recurs throughout the manuscript, reaching a point (in the middle of the passage on the great bards) where Shelley in frustration erases all alternatives:

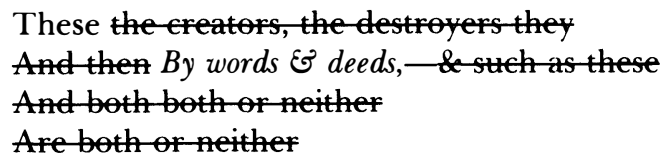

${ }^{17}$ Mary Shelley's reading text seems more faithful to ll. 127-28 of the manuscript than Reiman's, though by the same token it is less coherent. Mary Shelley's:

All but the sacred few who could not tame Their spirits to the conquerors-but as soon As they had touched the world with living flame,

Fled back like eagles to their native noon, Or those who put aside the diadem Of earthly thrones or gems ...

Were there, of Athens or Jerusalem, Were neither mid the might captives seen.

(ll. 128-35)

Reiman's:

All but the sacred few who could not tame Their spirits to the Conqueror, ... .

Were there;-for they of Athens \& Jerusalem Were neither mid the mighty captives seen.

(ll. 128-35)

The first version preserves a syntactic aporia that the second version corrects on the basis that Shelley must have meant to write what Reiman prints. In Mary Shelley's version the text begins by exempting the sacred few from involvement in life but then proceeds to an elaborate description of them in the course of which we almost forget the original "All 
Confusing words and deeds, and unable to distinguish creators from destroyers, this passage intervenes in the manuscript in such a way as to undo any meaningful contrast between the bards and Rousseau, between words that absorb life into art and verbal deeds that extend the infection of art into life. Nor does the disruptiveness of the passage end here. The fact that Shelley introduces, confuses, and then erases a distinction between creative and destructive power casts a shadow over his attempt, several lines later, to have Rousseau reintroduce the distinction. For the (op)position between Rousseau and the despots may simply be a displacement of the opposition between the bards and Rousseau: an attempt to wrest a position out of this tangle in which there are neither positive nor negative terms.

These passages of extreme aporia are (un)canceled, in the sense that a manuscript cannot sanitize their removal in the way that a reading text can. A related problem occurs in those cases where the cancellations are less definitive than they seem in edited versions. The passage on the great bards again provides an example. Because the manuscript contains no quotation marks, the attribution of certain words to certain characters is entirely speculative. Reiman, we recall, divides line 281 between Rousseau and 'Shelley' so as to strengthen Rousseau's opposition between himself and the bards, and so as to make it clear that 'Shelley' disagrees with Rousseau's equation of himself with Caesar and Constan-

but." The result is that it sounds as if Shelley is saying that the sacred few "Were there," and as if he then remembers what he set out to say and corrects himself by explaining that Jesus and Socrates "Were neither mid the mighty captives seen." Although it is possible to read the text logically by bracketing everything between "the sacred few" and "Were there," the logical reading is inhabited by a syntactic reading that keeps deferring it. Precisely because Mary Shelley's reading makes no grammatical sense, we are inclined to read the passage not just in terms of what Shelley was trying to say but also in terms of what he was having difficulty saying. Reiman takes the problematic juxtaposition of the lines "Were there" and "Were neither" and cleans it up by adding the clarifying phrase "For they." In fact, this phrase is only partly in the manuscript:

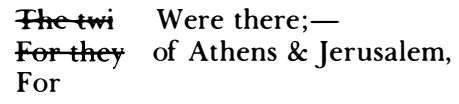

In his notes to his 1965 edition (cf. n.16) Reiman explains that he has restored the phrase "For they" that Shelley crossed out, because Shelley wrote in "For," thereby indicating that he meant to restore "For they." But it is just as likely that Shelley thought of restoring "For they" and then changed his mind. The aporia left in place by Mary Shelley's version is significant for two reasons: first, it is picked up later in the poem, when Rousseau's account of the procession begins to indicate that virtually no one is exempt from life; second, several canceled lines intervene between "of Athens and Jerusalem" and the line "Were neither mid the mighty captives seen," and in these lines Shelley again def ers the exemption of the sacred few, becoming increasingly fascinated by those who are in the procession. 
tine. Reiman's emendation of Mary Shelley's edition is based on the claim that Shelley inserted the words "I said" into the text and deleted the words "And then" in order to make place for them:

Even as the deeds of others- as
Ant he pointed to a company
I said

[Reiman's transcription]

But a closer look at the facsimile provided by Reiman shows that Shelley did not simply cancel "and then"; he canceled "And then he." The text, in other words, ought really to read "I said pointed to a company," which makes no sense unless we read its non-sense symptomatically. We can argue that Shelley meant to emend the text to write what Reiman prints. But it is just as possible that he made a change to which he was not clearly committed. Why, after all, did he not revise the text to read "I said and pointed to a company"? We will return yet again to this textual crux and to the way it unravels our attempts to read it and through it the poem. Suffice it to say that the manuscript shows Shelley making an incomplete change, and that that is why its editors render it differently. Moving between a version in which Rousseau repudiates himself and one in which 'Shelley' rehabilitates him, the poem seems doubtful about whether Rousseau really dismisses himself. But it is equally hesitant about having 'Shelley' leap to his defense. Uncertain whether to assign the revaluation of Rousseau to Rousseau or to 'Shelley,' the text projects and dislocates that revaluation, unsettling it when it reappears as a distinction between creative and destructive power but also blurring Rousseau's repudiation of himself.

By deferring the choice between alternatives, the manuscript's unfinished status allows it to inhabit the space of its own differences. The manuscript, in other words, forces any reading we might construct to confront those places where the poem refuses to become identical with itself. Those readings are based on reading texts that are themselves hermeneutic constructions, and it is to make this point that I focus on certain 'inaccuracies' in Reiman's transcription. But this is not to criticize the work of Shelley's editors, without which the text would be literally unreadable and without which this chapter could not be written. The manuscript, the reading texts, and the publication of the facsimile are all part of the poem's history, and it is not a question of choosing between them but rather of exploring their intertextual impact on each other. That impact is both constructive and recursive. Generations of scholars have not accepted the unreadability of the text, and their readings are 
now part of the text's history: supplements to which we can add but which we cannot subtract from the text. The fact that the manuscript was not left in a state in which it had neither form nor outline, the existence of the reading texts and of the hermeneutic constructions they have generated, these phenomena testify to what the poem itself images in the procession of dancers at its center. They are intertextual effects that reveal the way the human mind continues to construct meaning on the trace of its absence, as generations of readers participate in the life of the text and learn from themselves what they wanted to be taught by the poem. Until recently we could have made the dialectic of manuscript and text into the Sisyphean story of our triumph over life. But with the republication of the manuscript we have entered a further stage in the process of intertextual reading. If there was a phase in the poem's reception history when an editor could simply shape a work out of the manuscript and put the original behind her, that history is now a palimpsest that we must reenter each time we read the poem. The appearance of the Garland facsimile leads us to reflect on the ways in which different reading communities establish the identity of a text so as to legitimize their own philosophical or ideological positions, and on the strategies of transference that underlie our use of literature to reinvent ourselves.

The coexistence of reading texts and facsimile results, as we have already suggested, in a dialogue between technical and psychological reading. Our dialogue retraces the dialogue in Shelley's own mind, as he sought to represent that imageless anxiety (or perhaps excitement) that moved him to write the poem, recognizing all the while that nothing he wrote down had any finality. As we read the manuscript we feel in it a pressure toward what Schleiermacher calls 'composition' and 'meditation,' a pressure that has led Shelley's editors to complete his work by shaping the indefinite thought process into a finished thought complex. But we also feel the text's resistance to the selection and exclusion required by composition, and we feel it with a materiality that we cannot recover without returning to the manuscript. It seems that this particular poem was the site of Shelley's encounter with a radical textuality. To enter the contradictory palimpsest of the manuscript is to see that its utterances have no constative status. As Shelley sits down to write, he does not know 'that' the multitude are ignorant of what they are doing or 'that' they are self-aware. The significance of their actions comes into being in the moment of writing and is textualized rather than performed by its writing. Aware that events and characters have no mimetic status, Shelley writes with a sense that whatever he says can be said, and will then exist, quite differently. And given that knowledge, he can no longer write anything in the firm persuasion that it is so. The psychological reading encouraged by the manuscript, which does after all invite us to 
reconstruct the author's 'intention,' gives us back what Schleiermacher calls the 'discourse of the text,' and that discourse makes us aware that writing is subtended by a radical indeterminacy. What the discourse of the text is for the reader, speech is for Rousseau. Both are the medium in which we recover the sense of a perpetual difference within representation.

What are the consequences of this indeterminacy for the reader of the poem? Crucial to the hermeneutic process is our ability to locate characters with whom we can engage in some combination of identification and distance. Even the reading provided here assumes a Rousseau distinct from 'Shelley' and identifies with the former, or assumes that we can at least identify certain words as his. But one of the more extraordinary aspects of the manuscript is that Shelley did not use quotation marks, and that the editorial attribution of certain words to certain characters is entirely speculative. Though it is of ten clear (especially in longer passages) who is speaking, there are points at which the boundaries between Rousseau's and 'Shelley's' words are blurred, or where the speech of a character is not clearly demarcated from his unspoken thoughts. In the passage we have considered, for instance, there is no reason for Reiman to assign half rather than all of line 281 to 'Shelley.' If we look at the transcription, it seems that Shelley wrote "not as theirs" and not (as Reiman prints it in his reading text)" 'Not as theirs.'" The absence of the capital letter from "not" suggests that line 281 may be one sentence (fragment) spoken by one voice, albeit a referentially vague sentence. Attempting to limit this vagueness, Reiman substitutes a capital letter that is simply not in the manuscript and adds in his Norton critical edition a footnote that provides the referent of 'Shelley's' words. Rousseau condemns himself, according to Reiman, and 'Shelley' disagrees. But what if 'Shelley' speaks all of line 281 and Rousseau's part of the dialogue ends "And so my words have seeds of misery"? Because the addition of 'Shelley's' "I said" was clearly an afterthought, there is no means of knowing how much Shelley meant his persona to say and how he might have repunctuated the previous lines to accord with the reassignment of line 281 to 'Shelley.' To give all of line 281 to 'Shelley' is to make him agree with Rousseau's self-criticism. "Your words," 'Shelley' now says to Rousseau, "are like the vicious deeds of others, and are thus completely unlike the words of the bards."

My purpose is not to quibble with Reiman but to raise a larger question. The problem of who speaks which words is, at certain points, undecidable, and in adding a fourth version of line 281 I have resolved nothing. Even to try and decide the problem is to assume that Shelley meant to divide the dialogue clearly between the two characters and intended to add quotation marks later. But why, unless he meant to do 
so, should he have omitted only the quotation marks in a text that includes other forms of punctuation? Because he uses personal pronouns and character names, it is clear enough that Shelley expected the reader to try and assign words to characters. But it is also possible that he meant us to see such assignments as dubious, that he himself did not know who spoke what in a text that is, after all, a dream. At issue in the punctuation of the dialogue is the (dis)location of our readings. The assignment of specific words to specific characters has been a feature of all editions of this poem from Mary Shelley's to Reiman's, and has been responsible for our assumption that there are characters in this poem who have identities. Having constructed these characters, we can then assign certain positions to them, which enable us to interpret the poem in definite ways. Thus we can say with Bloom that Rousseau should have known better than to trust life, and we can see 'Shelley,' either from the beginning or at least by the end, as a locus for this insight. This identification of the insight a reader gains from the poem with a character in the text is a feature not only of traditional readings of The Triumph but also of socalled revisionary interpretations. My own analysis of the poem in Dark Interpreter, which argues that the poem reevaluates its rejection of Rousseau and thus of life, embodies this changed understanding in Rousseau, who stands in a relation of predictive parallelism to a 'Shelley' whose education remains incomplete because the poem is unfinished. But it is precisely the hermeneutic use of a character to confirm an interpretation that the manuscript questions. We are unable once and for all to identify 'Shelley' or Rousseau, and thus unable to locate whatever reading we have chosen in the text, as something that the text finally says.

This is not to say that Shelley dispenses with notions of character or identity. After all, he uses proper names and personal pronouns, and the burden of my argument has been that Rousseau in some sense survives, though it is far from clear for what he is a locus. What we experience in reading the manuscript is rather what Lacan calls the "fading" of the subject, a phenomenon that has been powerfully analyzed by Jane Gallop. Fading is not disappearance, but something more haunting: a presence that cannot be located and yet cannot be definitively renamed as absence so that we will cease searching for it. In Gallop's analysis it becomes an epistemological structure that makes us reflect on the status of a knowledge that seems to be in the text but that we cannot attribute to any specific person: author or character. Commenting on Lacan's idea in terms of her own experience of writing a chapter on Lacan's "Subversion of the Subject," Gallop speculates on why she feels compelled to set down as part of her interpretation a dream narrated by Freud, which is not the dream Lacan mentions in his essay, but which she thinks someone may have linked with the dream from Freud that Lacan does discuss. 
The association of the two dreams enables Gallop to 'understand' what Lacan has written. But as a scholarly source for her reading of his essay, 'Lacan' is in the process of fading and so, too, is the hypothetical critic who may have linked the two dreams but whom Gallop may also have imagined. And yet she feels compelled to see her reading of Lacan as coming from somewhere other than herself. ${ }^{18}$ Our position as readers of Shelley's text is very similar. We knew, when Bloom wrote his seminal chapter on The Triumph, that the text was critical of Rousseau for having been seduced by life. Yet with the re-editing of the poem that knowledge can no longer be clearly located in the text because it cannot be identified once and for all with the character 'Shelley.' As far as I am concerned, Bloom's reading has been replaced by my own knowledge that Rousseau achieves a certain measure of self-respect in the course of his conversation with 'Shelley.' Although the rehabilitation of Rousseau is tentative, I know that I gain a certain insight from reading the poem: an insight not into what he is but into his identity as the difference between positions that do not quite represent him. That Rousseau keeps speaking, that he does not simply fall silent when his interlocutors (life, 'Shelley,' or even Rousseau himself) negate his self-representations, suggests that he is that difference which consists not in anything he says but in the fact of speech. Yet this insight cannot be identified with a subject who is the source of my knowledge. Though it is intermittently given voice by Rousseau, I am troubled by the fact that he finally drops out of the poem, causing my insight to fade with him. Moreover, after reading the manuscript I can no longer quite locate Rousseau's words, which means that I must now ask myself whether it is not I who want 'Rousseau' to achieve self-respect because I still believe in the value of human life. But on the other hand, that knowledge is not my invention because I can point to specific passages in the text that account for my reading of it. The knowledge is somewhere in the text, produced and dislocated. Or rather, it is produced by my reading, but not purely in my reading. For I could not have told the text what I would have preferred to learn from it unless I had turned actor in this particular text.

The fading subject has significant consequences for a theory of reading, for the notion of fading applies not only to the author but also to the reader. Linking it with Barthes's notion of the death of the author, Gallop points out how much more complicated Lacan's subversion of the subject proves to be for a theory of reading. For Barthes the death of the author becomes, fairly unproblematically, the birth of the reader: "Proclaiming the death of the author asserts that one does not care, is not at all troubled by the still unknown source." 19 But the Lacanian subject is

${ }^{18}$ Jane Gallop, Reading Lacan (Ithaca, N.Y.: Cornell University Press, 1985), pp. 172-80. 19Ibid., p. 183. 
not a dead but a disappearing subject. The site of this (dis)appearance is the poem's first-person speaker: the 'Shelley' who, unlike Wordsworth in The Prelude, is not named, must be in quotation marks, but has not yet left his poem. Unable to locate Shelley or to locate him through his characters, we feel that our readings lack authority. But because Shelley is not dead, we also cannot invest them with our own authority, since they may not quite correspond to what he meant. As the question of authorial intentions recurs, the reader becomes subject to that very fading that brought her into being.

What Shelley meant remains important, because the fact that the poem survives as a manuscript frames the reader's response within the generic conventions of philology. It seems appropriate to conclude by considering Shelley's poem not simply as a thematization of reading, but intertextually as a scene of reading within the larger process of culture: one that generates new relationships between various critical positions. Perhaps by virtue of a historical accident, the poem survives as manuscript rather than text and thus induces an archeological attitude that preserves the hermeneutic impulse, but only as that which unsettles the identity of a performative reading. It is surely significant that hermeneutics survives only as that which introduces difference into reading. Among the cultural effects of this manuscript is the fading, not the death or the rebirth, of hermeneutics. But the fading of hermeneutics is also the difference between its consolidation and its dismemberment. In other words, the fact that the hermeneutic reappears at the site of the poem's deconstruction, that our reading of the text is undone by our attempt to re-member what Shelley actually wrote, is the reason why it is insufficient to see the manuscript as the disfiguration of the printed text(s). The manuscript, it is true, obliterates the printed text: as we struggle with it, our brains become as sand, and the traces of what we have previously constructed from our reading are ef faced, "half erased" (ll. 405-407, SPP). But this dis-figuration takes the form of a psychological reading in which the forgetting of one reading allows us to remember another: to recover something else that Shelley might have meant. Or to put it differently, among the cultural effects produced by the manuscript is also the fading of deconstruction. 